МАТЕМАТИЧЕСКОЕ МОДЕЛИРОВАНИЕ РАСПРЕДЕЛЕНИЯ НАПРЯЖЕНИЙ В ОБЛУЧЕННОМ ИОНАМИ ВЫСОКИХ ЭНЕРГИЙ АЛМАЗЕ

\author{
И.А. Хорунжий ${ }^{1}$, В.А. Мартинович ${ }^{1}$, М.С. Русецкий ${ }^{2}$, В.Н. Казючиц ${ }^{2}$, Н.М. Казючиц ${ }^{2}$ \\ ${ }^{1}$ Белорусский национальный технический университет, Беларусь, Минск, \\ igor.khorunzhii@newmail.ru,valeriiam@yahoo.com \\ ${ }^{2}$ Белорусский государственный университет, Беларусь, Минск, \\ rusetsky@bsu.by,kazuchitsvn@bsu.by,kazuchits@bsu.by
}

\begin{abstract}
Аннотация. Получено распределение напряжений в синтетическом алмазе, облученном ионами Хе с энергией 167 МэВ флюенсом 3.55·10 см$^{-2}$, методом компьютерного моделирования. Показано, что расширение решетки в облученном слое приводит к изгибу алмазной пластины, а необлученная часть находится под действием сжимающих напряжений, которые распределены неравномерно. Наблюдается хорошее соответствие между расчетными и экспериментальными данными, полученными методами комбинационного рассеяния света и конфокальной микроскопии.
\end{abstract}

Ключевые слова: синтетический алмаз, высокоэнергетичная ионная имплантация, распределение напряжений, численное моделирование.

\title{
MATHEMATICAL SIMULATION OF STRESS DISTRIBUTION IN HIGH-ENERGY IONS IRRADIATED DIAMOND
}

\author{
I.A. Khorunzhii ${ }^{1}$, V.A. Martinovich ${ }^{1}$, M.S. Rusetsky ${ }^{2}$, V.N. Kazuchits ${ }^{2}$, N.M. Kazuchits ${ }^{2}$ \\ ${ }^{1}$ Belarusian National Technical University, Belarus, Minsk, \\ igor.khorunzhii@newmail.ru,valeriiam@yahoo.com \\ ${ }^{2}$ Belarusian State University, Belarus, Minsk, \\ kazuchitsvn@bsu.by,rusetsky@bsu.by,kazuchits@bsu.by
}

\begin{abstract}
The stress distribution in synthetic diamond irradiated with $167 \mathrm{MeV} \mathrm{Xe}$ ions to the fluence of $3.55 \cdot 10^{14} \mathrm{~cm}^{-2}$ has been obtained by numerical simulation. It is shown that the lattice expansion in irradiated layer leads to bending of the diamond plate, and the unirradiated part is under nonuniformly distributed compression stresses. There is a good correlation between the calculated and experimental data obtained by Raman scattering and confocal microscopy methods. Keywords: synthetic diamond, high-energy ion irradiation, stress distribution, numerical simulation.
\end{abstract}

Алмаз является полупроводниковым материалом, на основе которого изготавливаются детекторы ионизирующих излучений, фотоприемники, лазеры, диоды, транзисторы, теплоотводы и др. Уникальные по сравнению с другими полупроводниками свойства алмаза, такие как большая ширина запрещенной зоны, высокая подвижность носителей заряда, высокая электрическая прочность, повышенная температурная и радиационная стойкость, высокая теплопроводность, химическая инертность, делают алмаз перспективным материалом для применения в различных областях электроники, оптики и техники в целом. Приборы на основе природных алмазов получаются дорогими. Основное ограничение на использование природных алмазов накладывают их отличия, что затрудняет организацию серийного производства. В связи с этим изучение свойств синтетических алмазов и их изменения при изготовлении алмазных приборных структур является актуальной задачей.

Одним из основных технологических инструментов при создании приборных структур является ионная имплантация. Применительно к алмазу этот метод используют длительное время [1]. Известно о создании проводящих слоев на поверхности алмаза, изучены условия, при которых происходит восстановление кристаллической структуры, поврежденной вследствие облучения. Особый интерес представляет имплантация ионами высоких энергий из-за возможности формирования заглубленных легированных слоев.

Недостатком ионной имплантации является образование в облученном кристалле большого числа вакансий и смещенных атомов. Радиационные повреждения 
кристаллической решетки приводят к её разбуханию $[2,3]$. Как следствие, на границе между облученным и неповрежденным слоями кристалла возникают механические напряжения. При внедрении ионов с низкими энергиями (десятки, сотни кэВ) имплантированный слой локализован близко (менее 1 мкм) к поверхности и напряжения в значительной степени релаксируют за счет этого. При имплантации высокоэнергетических ионов (десятки, сотни МэВ) внедренная примесь локализована на глубине десятки микрометров. Это приводит к возникновению в имплантированном слое алмаза гигантских напряжений. Напряжения в этом случае распространяются на большую глубину и распределены неравномерно [3].

Целью настоящей работы является численное моделирование распределения напряжений в синтетическом алмазе, имплантированном ионами Хе с энергией 167 МэВ и сравнение расчетных и экспериментальных данных.

В работе [3] методами комбинационного рассеяния света (КРС) и конфокальной микроскопии исследовано распределение напряжений в синтетическом алмазе, имплантированном ионами Хе с энергией 167 МэВ. Величина напряжений определялась по сдвигу линии однофононного рассеяния $1332 \mathrm{~cm}^{-1}$ при поперечном сканировании возбуждающего КРС лазерного излучения. Значения среднего пробега ионов $\mathrm{R}_{\mathrm{p}}$ и значения разброса пробега $\Delta \mathrm{R}_{\mathrm{p}}$, рассчитанные с помощью программы TRIM, составили 10.67 и 0.44 мкм, соответственно. Концентрация вакансий на один внедренный ион изменялась от $2.24 \cdot 10^{6} \mathrm{~cm}^{-3}$ в приповерхностном слое до $6.66 \cdot 10^{7} \mathrm{~cm}^{-3}$ в окрестности проективного пробега ионов (рис. 1).

В имплантированном ионами слое кристаллическая решетка была расширена, а распределение напряжений следовало за распределением вакансий и имело максимум в окрестности проективного пробега. За пробегом ионов Хе распределение напряжений зависело от флюенса имплантации. Для малых флюенсов имплантации расширяющие решетку напряжения монотонно уменьшались с глубиной. Для больших флюенсов имплантации распределение напряжений за пробегом имело более сложный характер: за областью расширения решетки следовала область

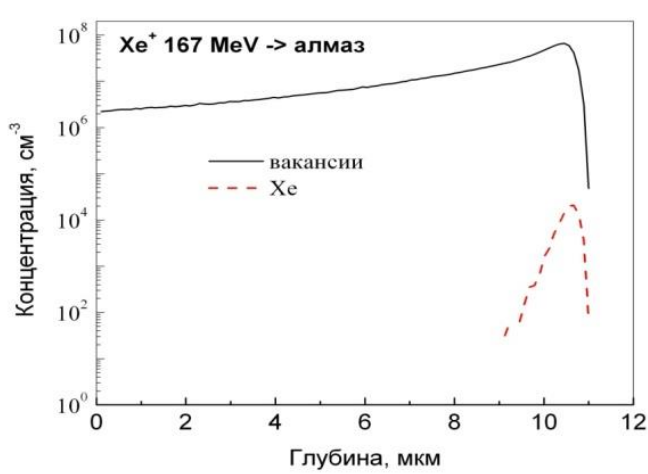

Рис. 1. Рассчитанные с помощью TRIM распределения в алмазе первичных вакансий и ионов Хе с начальной энергией 167 МэВ; флюенс равен $1 \mathrm{~cm}^{-2}$ сжатия, которая монотонно релаксировала с глубиной. Следует отметить, что технические характеристики использованной в [3] установки позволяли измерять распределения напряжений вдоль поперечного сечения облученной пластины алмаза на глубинах не более 25 мкм.

При моделировании рассматривался случай имплантации флюенсом ионов равным $3.55 \cdot 10^{14} \mathrm{~cm}^{-2}$. Ранее нами использована модель, в которой облученная область пластины алмаза реального размера разбита на две части, одна из которых (до глубины залегания примеси) содержала вакансии с постоянной концентрацией вдоль пробега, другая (глубина залегания примеси) - вакансии и ионы примеси. Для расчета напряжений использовались численные значения концентрации вакансий и примеси, полученные из TRIM. Получено хорошее соответствие между расчетными и экспериментальными значениями напряжений за глубиной пробега. В области 
залегания примеси значение напряжения оказалось завышенным на порядок, что потребовало дальнейшего развития модели.

В данной работе описывается модель, в которой учтено неоднородное распределение вакансий вдоль пробега ионов. Облученная область пластины алмаза разбита на три части, каждой из которых соответствует свое значение концентрации вакансий. Увеличение концентрации вакансий вызывает пропорциональное увеличение объема кристалла, что можно представить в виде эквивалентного теплового расширения. Моделирование термонапряжений использовалось для расчета напряжений, возникающих и при имплантации ионов. Изменению концентрации вакансий в различных слоях соответствовали разные коэффициенты теплового расширения, которые обеспечивали требуемое увеличение объема при нагреве на $100^{\circ} \mathrm{C}$, следующим образом:

$$
n / n_{0}=1+\beta \Delta t
$$

где $n_{0}-$ концентрация атомов в необлученном образце; $n$ - суммарная концентрация атомов и добавленных вакансий; $\beta$ - коэффициент объемного теплового расширения. При этом предполагалось, что необлученная часть кристалла при нагревании не расширялась.

На рис. 2 представлен сгенерированный компьютерной программой внешний вид алмазной пластины после имплантации. Видно, что разбухание решетки в имплантированном слое и появление напряжений приводят к изгибу всей пластины, как и наблюдалось в экспериментах [3].
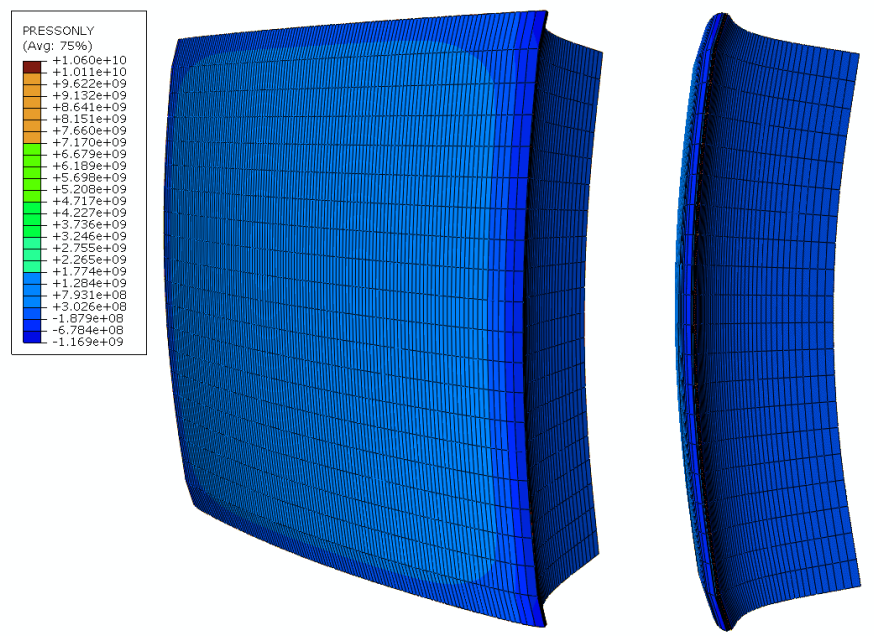

Рис. 2. Сгенерированная компьютерной программой модель алмазной пластины, имплантированной ионами Хе с энергией 167 МэВ флюенсом 3.55·10 ${ }^{14} \mathrm{~cm}^{-2}$

Из рис. 2 видно, что напряжения вдоль имплантированной поверхности алмазной пластины распределены неравномерно. Если край пластины находится под действием расширяющих напряжений величиной от 0.4 до 1.1 ГПа, то большая часть поверхности пластины (на расстояниях более 150 мкм от периметра) испытывает сжимающие напряжения величиной около 0.5 ГПа.

На глубине залегания примеси (10.45 мкм) наблюдаются максимальные сжимающие напряжения, составившие 10 ГПа, что полностью соответствует данным, полученным из эксперимента.

На рис. 3 показано распределение напряжений по глубине вдоль поперечного сечения (торца) алмазной пластины за пробегом ионов Хе. Распределения приведены для случая возбуждения КРС на глубине 5 мкм от поверхности поперечного сечения пластины (экспериментальные точки из [3]), и на глубинах 0,25 и 150 мкм от поверхности поперечного сечения пластины, рассчитанные теоретически (кривые 0,25 
и 150 мкм, соответственно). Отметим, что рассчитанное распределение для 25 мкм соответствует максимальной глубине возбуждения КРС при поперечном сканировании в экспериментах [3].

Из рис. 3 следует, что вид кривой поперечного распределения напряжений в имплантированной ионами алмазной пластине зависит от расстояния до периметра пластины. Так, на поверхности поперечного сечения пластины расширение решетки, соответствующее отрицательным значениям давления, на глубине 30 мкм меняется на сжатие, что соответствует положительным значениям давления. Сжатие усиливается до 70 мкм и не исчезает вплоть до противоположной поверхности пластины. Большая часть рассчитанной кривой хорошо согласуется с измеренными в [3]

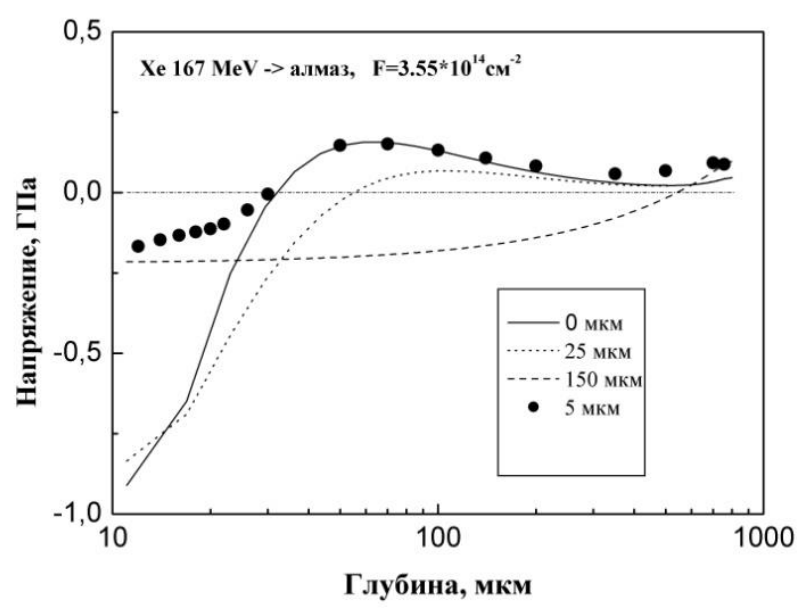

Рис. 3. Распределение напряжений в алмазной пластине за пробегом ионов Хе для флюенса $3.55 \cdot 1014$ см-2: рассчитанные значения показаны линиями, экспериментальные - взятыми из [3] точками

значениями. Заметные различия наблюдаются только в окрестности проективного пробега ионов Хе. На глубине 25 мкм от поверхности поперечного сечения расширение решетки меняется на сжатие на глубине 70 мкм, а в области 150 мкм от поверхности - в окрестности 600 мкм. Таким образом, практически вся имплантированная пластина (за вычетом областей на расстоянии около 150 мкм вдоль её периметра) находится под действием расширяющих кристаллическую решетку напряжений, которые монотонно уменьшаются к неимплантированной поверхности. Приповерхностный слой толщиной около 200 мкм со стороны неимплантированной поверхности пластины находится под действием сжимающих напряжений.

Анализ результатов показал, что наблюдается хорошее качественное и количественное соответствие между данными [3], полученными из анализа спектров КРС алмаза, облученного ионами Хе с энергией 167 МэВ флюенсом $3.55 \cdot 10^{14}$ см$^{-2}$, и результатами численного моделирования. Обнаружено, что расширение решетки в облученном слое приводит к изгибу всей алмазной пластины, где необлученная часть алмаза находится под действием сжимающих напряжений, распределение которых носит сложный характер.

Библиографический список

1. Вавилов В.С. Возможности и ограничения ионной имплантации в алмаз и их сопоставление с другими методами введения электрически активных примесей // Успехи физических наук. 1994. Т. 164. № 4. С. 429-433.

2. Prins J.F., Derry T.E., Sellschop J.P.F. Volume expansion of diamond during ion implantation // Physical Review B. 1986. T. 34. № 12. C. $8870-8874$.

3. Raman scattering in diamond irradiated with high-energy xenon ions / N.M. Kazuchits, O.V. Korolik, M.S. Rusetsky, V.N. Kazuchits, N.S. Kirilkinb, V.A. Skuratov // Nuclear Instruments and Methods in Physics Research Section B: Beam Interactions with Materials and Atoms. 2020. T. 472. C. 19-23. 